\title{
ALAT MONITORING PADA DEPO AIR MINUM BIRU CABANG NAGRAK KOTA TANGERANG MENGGUNAKAN AIR GALON BERBASIS SMS GATEWAY
}

\author{
Desy Apriani ${ }^{1}$ \\ Kharis Munawar ${ }^{2}$ \\ Ade Setiawan ${ }^{3}$ \\ Dosen STMIK Raharja ${ }^{1}$ \\ Magister Teknik Informatika STMIK Raharja ${ }^{2}$ \\ STMIK Raharja Jurusan Sistem Informasi ${ }^{3}$ \\ Jl. Jendral Sudirman No. 40, Modern Cikokol, Tangerang ${ }^{1,2,3}$ \\ Email :desy@raharja.info ${ }^{1}$, kharis.munawar@raharja.info ${ }^{2}$, ade.setiawan@raharja.info ${ }^{3}$
}

\begin{abstract}
ABSTRAK
Perkembangan teknologi komputer secara signifikan telah menjadi kebutuhan dalam meningkatkan mutu pelayanan kepada konsumen. Penerapan dari perkembangan teknologi komputer ini berupa alat yang akan memonitoring ketersediaan air, dan akan mengirimkan notifikasi SMS kepada pegawai untuk melakukan pemesanan jika ketersediaan air sudah habis. Alat ini menggunkan Arduino Uno sebagai pusat kendali, serta menggunakan IR LED sebagai pembaca dari kondisi air dalam gallon. Selain itu, alat ini dilengkapi dengan GSM Modul yang berfungsi untuk mengirimkan notifikasi berupa SMS. Dengan adanya alat ini, maka akan mempermudah pegawai tanpa harus berkeliling mencari konsumen, serta memudahkan konsumen tanpa harus mengunjungi Depo Air Minum untuk melakukan pengisian.
\end{abstract}

Kata Kunci : Air Minum, Arduino Uno, IR LED, GSM Modul

\begin{abstract}
The development of computer technology has significantly become needs in improving the quality of service to consumers. The application of computer technology development is a tool that will monitor the availability of water, and will send an SMS notification to the employee to make a booking if the availability of water is up. This tool either using the Arduino Uno as the control center, as well as use IR LEDS as a reader from the condition of the water in a gallon. In addition, this tool is equipped with a GSM module which serves to send a notification in the form of SMS. The existence of this tool, it will make it easier to employees without having to drive around looking for consumers, as well as make it easier for consumers without having to visit the Depot drinking water to do the charging.
\end{abstract}

KeyWords: Drinking Water, The Arduino Uno, IR LEDS, GSM Module

\section{PENDAHULUAN}

Air minum adalah air yang telah melalui tahap pengolahan dan memenuhi syarat kesehatan untuk dikonsumsi. Selain itu air merupakan kebutuhan yang penting dan utama bagi manusia untuk kelangsungan hidupnya. Depo Air Minum Biru merupakan perusahaan yang bergerak dibidang pengolahan dan pengisian air minum yang layak dikonsumsi untuk memenuhi kebutuhan masyarakat sekitar. Dengan sistem yang berjalan saat ini, pegawai dari Depo Air Minum Biru harus berkeliling mengunjungi tiap - tiap 
rumah dari konsumen yang tentunya akan memakan banyak waktu. Salah satu perkembangan teknologi komunikasi bebasis IOT (internet of things) adalah SMS GATEWAY. SMS GATEWAY merupakan sebuah gerbang yang menghubungkan antara komputer dengan konsumen melalui SMS. Teknologi ini telah banyak diaplikasikan pada sistem penjualan barang dan jasa. Depo Air Minum Biru dapat mencoba mengaplikasikan teknologi SMS GATEWAY pada sistem pelayanan permintaan langsung air minum yang layak dikonsumsi ke tiap-tiap rumah konsumen (door to door).

\section{RUMUSAN MASALAH}

PT. Arka Mahesa Pratamamasih belum memiliki iklan sehingga PT. Arka Mahesa Pratama ber keinginan membuat video iklan agar banyak di lihat dan dapat di ketahui oleh masyarakat.

\section{METODE PENELITIAN}

\section{Pengertian sistem}

Kumpulan dari sub-sub sistem abstrak yang saling terintegrasi dan berkolaborasi untuk mencapai sutau tujuan tertentu.

\section{Pengertian Data}

Suatu fakta yang berbentuk input dengan menghasilkan informasi

\section{Pengertian Analisa Sistem}

Penguraian dari suatu sistem informasi yang utuh kedalam bagian-bagian komponennya dengan bermaksud untuk mengidentifikasikan dan mengevaluasi permasalahan.

\section{Pengertian Pengujian}

Suatu program dengan tujuan menemukan suatu kesalahan.

\section{Pengertian Monitoring}

Merupakan suatu aktivitas yang bertujuan untuk memantau atau mengamati sesuatu.

\section{Pengertian Mikrokontroler}

Sebuah sistem komputer fungsional dalam sebuah chip.

\section{Pengertian Arduino}

Kit elektronik atau papan rangkaian elektronik open source yang di dalamnya terdapat komponen utama.

\section{Pengertian SMS Gateway}

Suatu sistem yang menjembatani antara handphone dengan sistem yang menjadi server dengan SMS sebagai informasinya.

\section{Pengertian Sensor}

Suatu alat yang merubah dari besaran fisika menjadi besaran listrik. 


\section{Pengertian Sensor Infrared}

Alat elektronik yang digunakan untuk merasakan karakteristik tertentu dari lingkungannya oleh baik memancarkan dan / atau mendeteksi radiasi inframerah.

\section{Pengertian Komponen Elektronika}

Sebuah alat berupa benda yang menjadi bagian pendukung suatu rangkaian elektronik yang dapat bekerja sesuai kegunaannya.

\section{Diagram Blok}

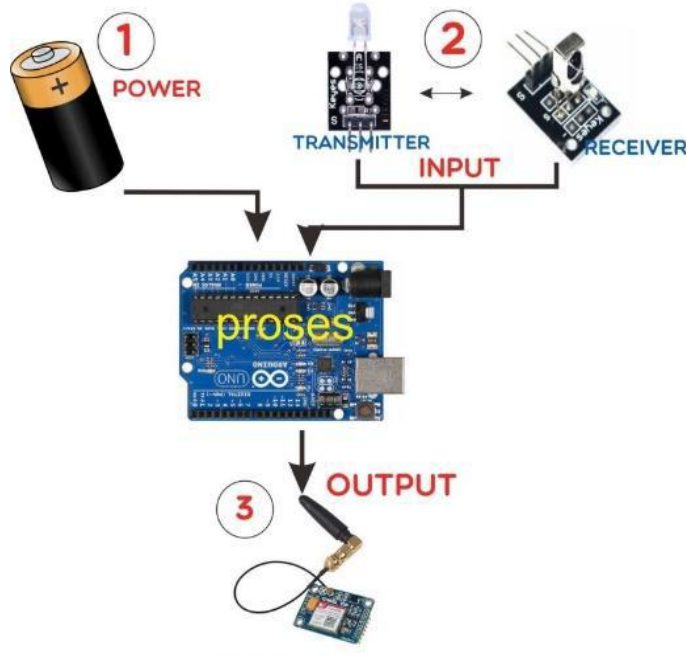

Gambar 1. Diagram Blok

\section{Flowchart Sistem}

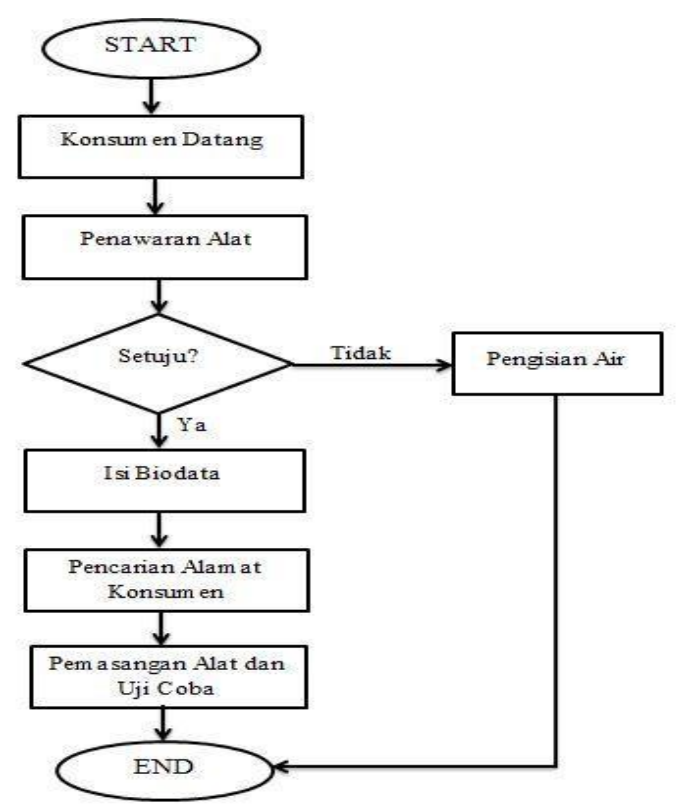

Gambar 2. Flowchart Sistem Yang Diusulkan 


\section{Flowchart Cara Kerja Alat}

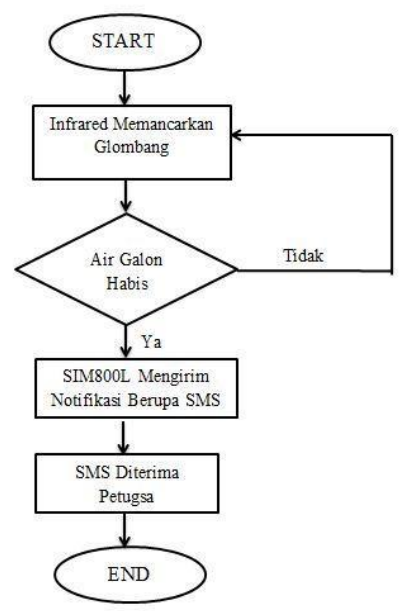

Gambar 3. Flowchart Cara Kerja Alat

\section{Spesifikasi Hardware}

1. Personal Computer (PC) : PC yang digunakan memiliki spesifikasi dengan prosesor intel core i5 2,67 GHz, Memory 2GB DDR3, dan harddisk 500 GB. PC ini nantinya akan digunakan sebagai pengolah dari software yang digunakan dalam pembuatan rancangan dan program.

2. Arduino Uno : Sebuah board mikrokontroler yang berfungsi sebagai otak yang akan mengolah semua informasi dan perintah pada robot yang akan dirancang.

3. Sensor Infrared : - Infrared transmitter : sensor infrared ini berfungsi untuk memancarkan frekuensi. - Infrared Receiver : sensor infrared ini berfungsi untuk menangkap frekuensi yang di pancarkan oleh infrared transmitter

4. GSM Module : Modul GSM ini berjenis SIM800L V2. GSM modul ini yang nantinya mengirim notifikasi berupa SMS.

5. Kabel Jumper : Penghubung antar satu komponen ke komponen lain.

\section{Spesifikasi Software}

1. Microsoft Office : Menggunaka office 2010 untuk proses pembuatan secara tertulis mengenai perancangan dan laporan skripsi.

2. Arduino IDE : Sebuah aplikasi pemrograman berbasis bahasa C yang sudah disederhanakan, aplikasi ini yang akan digunakan untuk menuliskan program dan ditanam pada board arduino uno.

3. UC Browser : Sebuah aplikasi web browser untuk mencari referensi. 


\section{Rangkaian Infrared Transmitter}

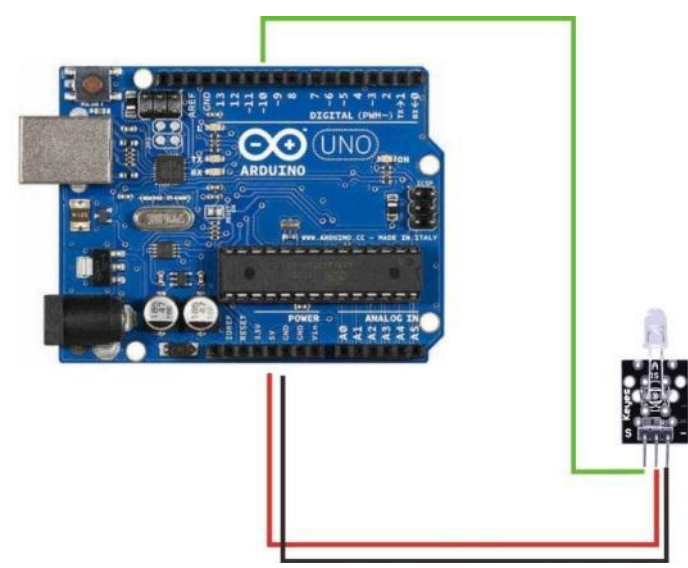

Gambar 4. Rangkaian Infrared Transmitter

\section{Rangkaian Infrared Receiver}

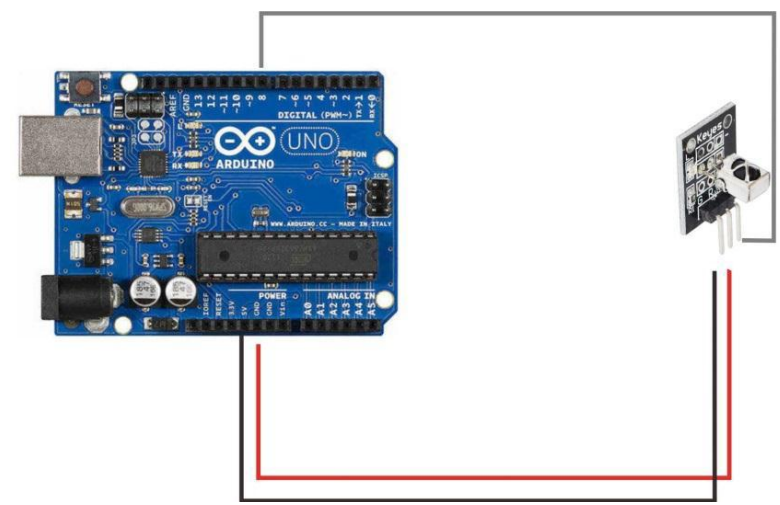

Gambar 5. Rangkaian Infrared Receiver

\section{Rangkaian SMS Module}

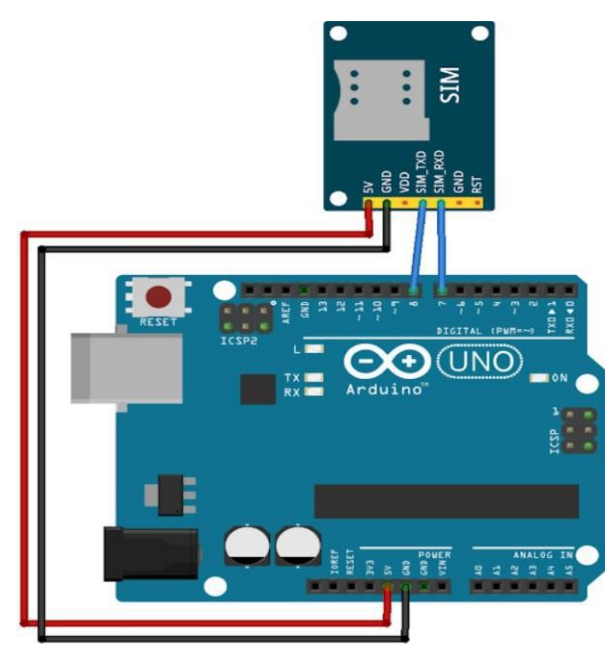

Gambar 6. Rangkaian SMS Module 


\section{Perancangan Sofware}

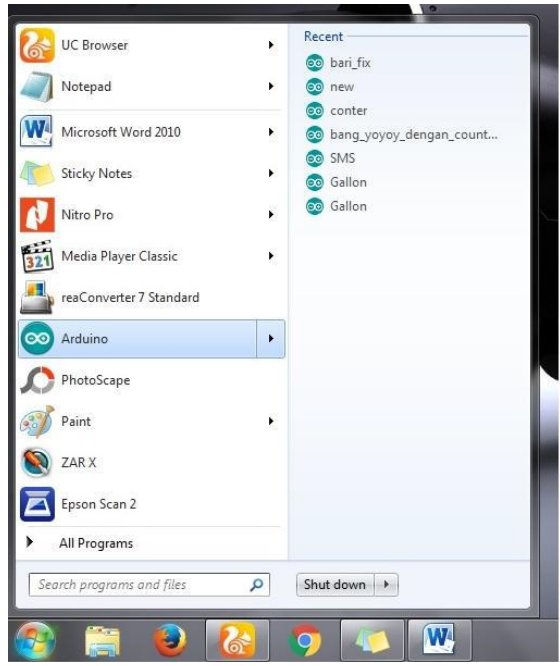

Gambar 7. Membuka Software Arduino
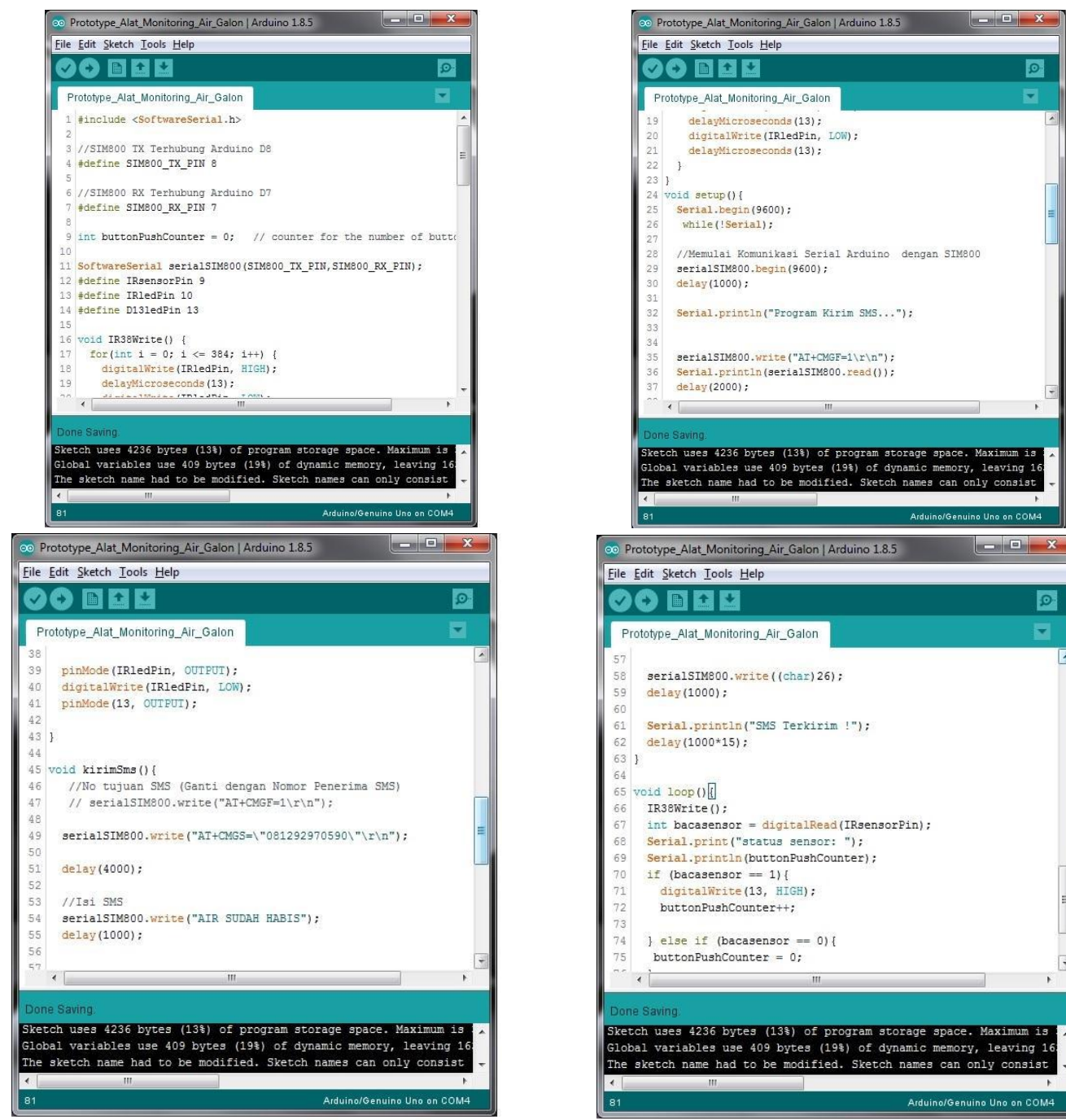

$\infty$ Prototpe_Alt_Moninging Air_Galon | Arduino 1.85
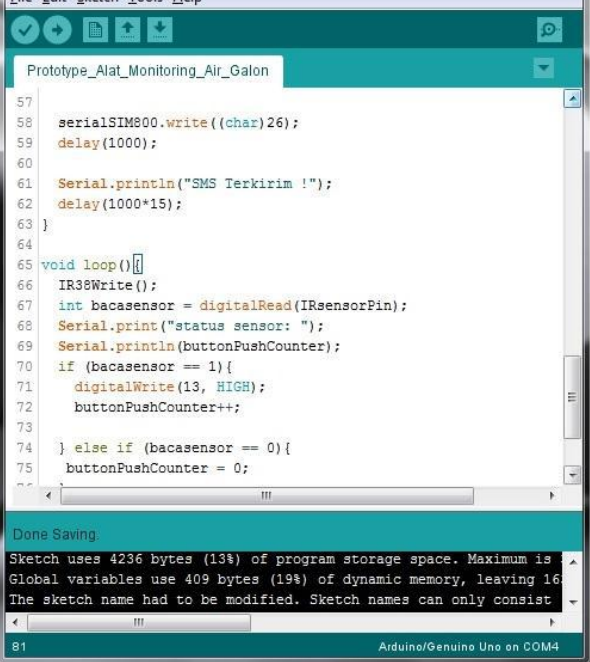

Gambar 8. Penulisan Code Program 


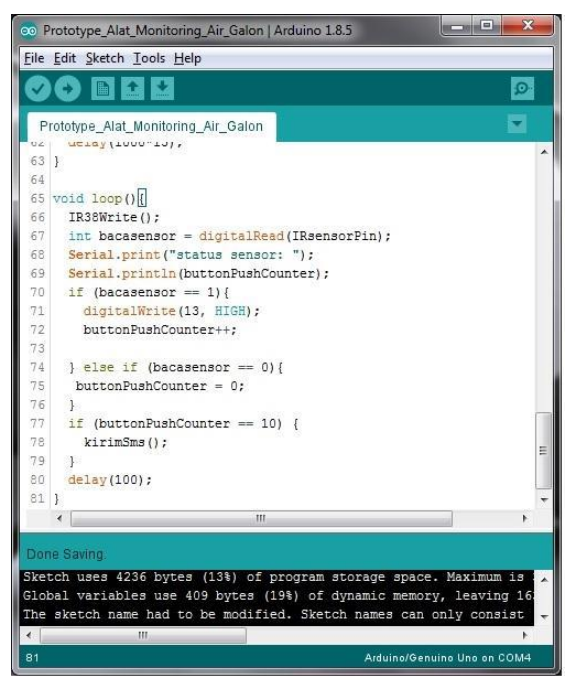

Gambar 9. Kompilasi Listing Program

Gelombang dari sensor infrared tidak menembus galon sebagai indikator galon dalam keaadan terisi air. Hasil pada serial monitor menampilkan angka 0 sebagai indikator air galon masih terisi
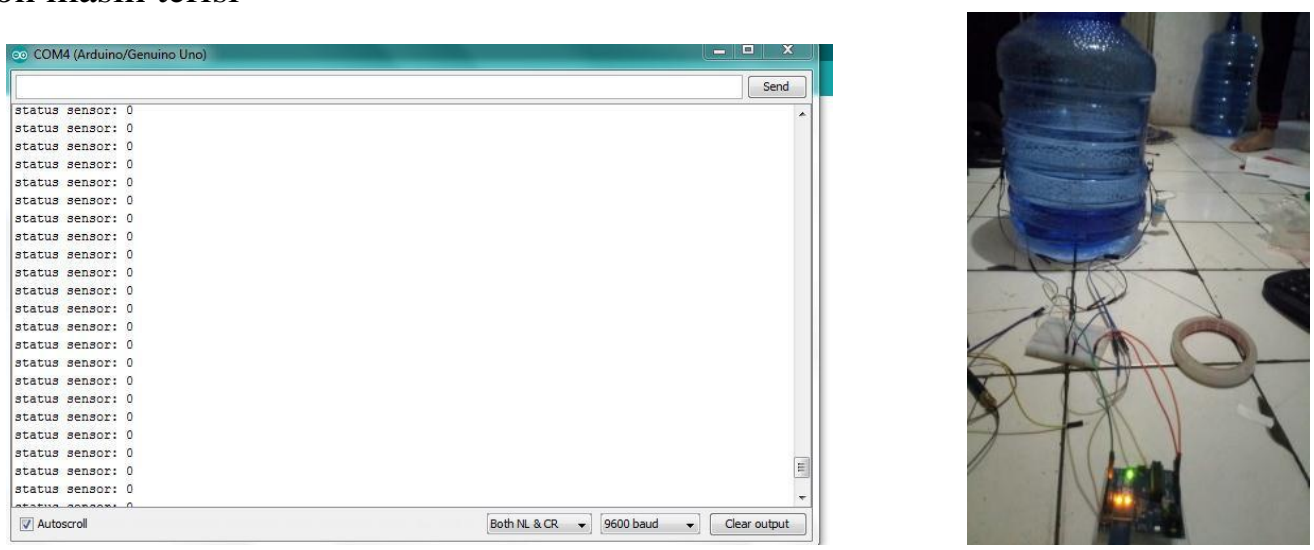

Gambar 10. Pengujian galon dalam keadaan isi

Gelombang dari sensor infrared menembus galon sebagai indikator galon dalam keaadan kosong. Hasil pada serial monitor menampilkan angka 1-9 sebagai indikator air galon kosong, dan menghasilkan status SMS terkirim.
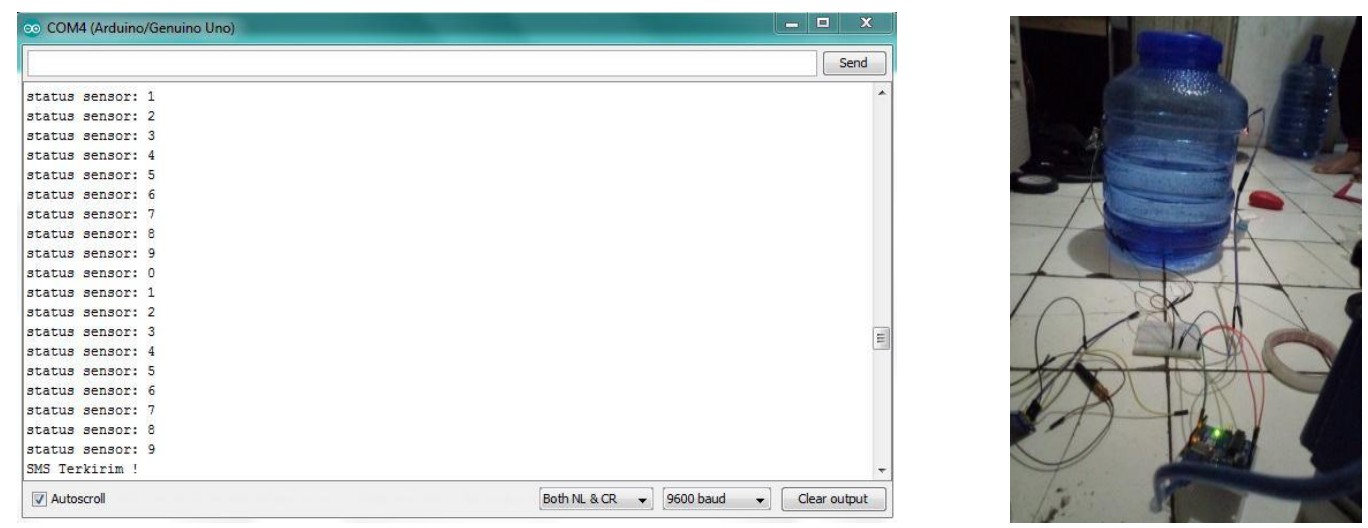

Gambar 11. Pengujian galon dalam keadaan kosong 
Indikator LED SIM800L menyala sebagai tanda SIM800L mengirim SMS. Serial monitor menghasilkan setatus TERKIRIM dan handphone petugas menerima SMS.
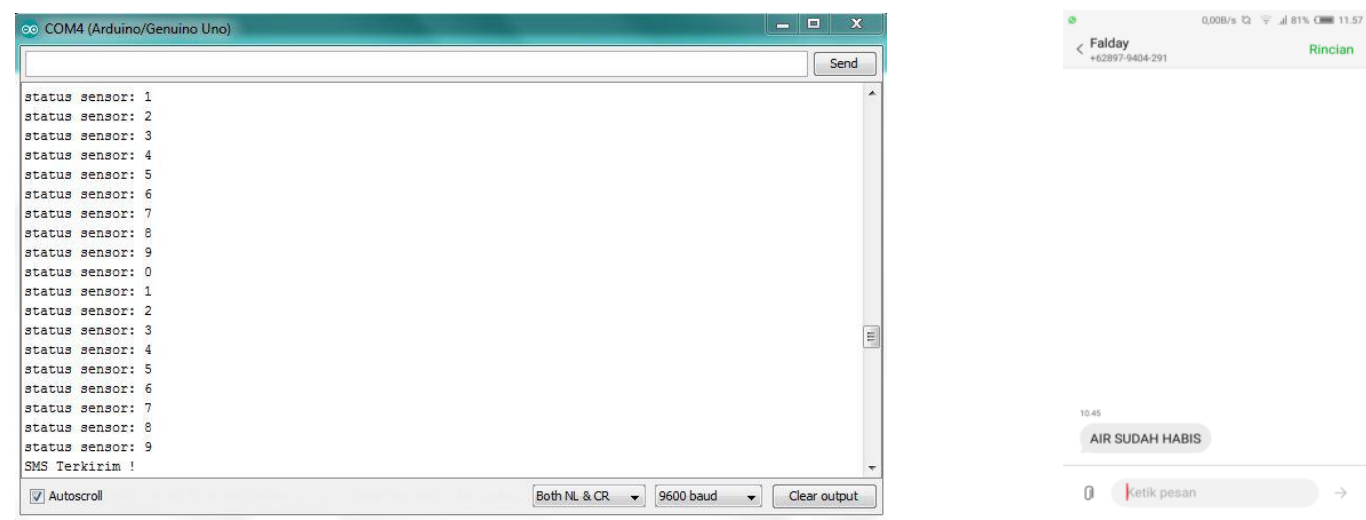

Gambar 12. Pengujian SIM800L mengirim SMS

\section{LITERATUR REVIEW}

1. Penelitian yang dilakukan oleh Suherman, Irwin Andriyanto, dan Saleh Dwiyatno dari Universitas Serang Raya yang berjudul “ Rancang Bangun Alat Ukur Temperatur Suhu Perangkat Server Menggunakan Sensor Lm35 Bebasis SMS Gateway " pada tahun 2015. Penelitian ini membahas tentang alat pengukur suhu menggunakan sensor LM35 yang kemudian informasi pembacaan tersebut diteruskan menjadi sebuah informasi atau output menggunakan teknologi SMS Gateway.

2. Penelitian yang dilakukan oleh Dani Sasmoko, dan Arie Mahendra dari Universitas Muara Kudus yang berjudul "Rancang Bangun Sistem Pendeteksi Kebakaran Berbasis Iot dan Sms Gateway Menggunakan Arduino " pada tahun 2017. Penelitian ini membahas tentang perancangan alat yang befungsi sebagai pendeteksi kebakaran. Perancangan ini menggunakan ESP8266 berbasis IOT sebagai pusat kendali dan informasi yang di dapat akan diteruskan menjadi sebuah informasi menggunakan teknologi SMS Gateway.

3. Penelitian yang dilakukan oleh Ikhsan Parinduri dari STMIK Royal Kisaran yang berjudul "Prototype Kartu Pintar Kamar Tidur Menggunakan Sensor Infrared Dan Photodioda Berbasis Arduino Uno" pada tahun 2017. Penelitian ini membahas tentang otomatisasi perangkat yang terdapat pada kamar tidur dengan memanfaatkan pantulan yang dihasilkan dari sensor infrared yang kemudian akan diteruskan menjadi perintah untuk relay menyalakan atau mematikan perangkat.

4. Penelitian yang dilakukan oleh Mira Afrina, dan Ali Ibrahim dari Universitas Sriwijaya yang berjudul “ Pengembangan Sistem Informasi SMS Gateway Dalam Meningkatkan Layanan Komunikasi Sekitar Akademika Fakultas Ilmu Komputer Unsri " pada tahun 2015. Penelitian ini membahas tentang pemanfaatan teknologi SMS Gateway untuk berkomunikasi disekitar lingkungan kampus.

5. Penelitian yang dilakukan oleh Nurmalia Nasution, Amir Supriyanto dan Sri Wahyu Suciyati dari Universitas Lampung yang berjudul “ Implementasi Sensor Fotodioda 
sebagai Pendeteksi Serapan Sinar Infra Merah pada Kaca “ pada tahun 2015. Penelitian ini membahas tentang pembacaan nilai sinar infra merah menggunakan sensor photodiode pada bidang kaca.

\section{KESIMPULAN}

Dalam meningkatkan mutu pelayanan kepada konsumen air biru, diperlukan fasilitas yang dapat mempermudah setiap konsumen air biru khususnya dalam proses pemesana air yang layak dikonsumsi. Telah diketahui penerapan proses pemesanan air masih berjalan secara manual atau door to door dimana pegawai air biru dengan konsumen harus bertemu dan beratatap muka seacara langsung untuk menyepakati pemesanan serta pengantaran air galon. Tentunya hal ini berjalan kurang maksimal pada proses pengantaran dan pemesanan air galon serta memakan waktu yang cukup lama. Selain itu, proses manual seperti ini akan menambah beban kerja terhadap pegawai air biru diantaranya harus berkeliling mengunjungi tiap - tiap rumah serta dari sisi konsumen, konsumen masih harus menelpon, menunggu pegawai datang maupun harus mengunjungi secara langsung ke depo air biru.

\section{DAFTAR PUSTAKA}

[1] Afrina, M., Ibrahim, A. 2015. "Pengembangan Sistem Informasi SMS Gateway Dalam Meningkatkan Layanan Komunikasi Sekitar Akademika Fakultas Ilmu Komputer Unsri”. Universitas Sriwijaya. Jurnal Sistem Informasi (JSI), Vol \&, No. 2. ISSN Print 2085-1588.

[2] Afrizal, Aldy. 2014. Rancang Bangun Sistem Informasi Monitoring Penjualan PT. Fitrafood : Universitas Islam Negeri Syarif Hidayatullah Jakarta.

[3] Athira, K. R., Aiswarya, S. N., Haritha, S., Krishnapriya, S. N., Riji, M. T., and Priyalakshmi, S. 2016. "Infrared sensor based 3D image construction". Department of Electronics and Communication Engineering. International Research Journal of Engineering and Technology (IRJET), Vol. 03, Issue 04. e-ISSN: 2395 -0056.

[4] Dewi, Meta Amalya, et al. (2014). Penggunaan Ekstention Waktu Dalam Role Online System Ticketing Raharja (Rooster) Sebagai Penunjang Pelayanan Iduhelp.Jurnal CCIT. Vol (1), 125.

[5] Hartono, Bambang. 2013. Sistem Informasi Manajemen Berbasis Komputer. Jakarta : PT Asdi Mahasatya.

[6] Jimoh, R. G., COCO, K. B., OLUOBO, Abdel, M. F. O. 2014. "DESIGN OF MOBILE SHORT MESSAGE SERVICE (SMS) ACROSS A COMPUTER NETWORK FOR ORGANISATIONAL COMMUNICATION". University of Ilorin. International Journal of Computer Applications Technology and Research. Vol. 2. Issue 4. ISSN: 2319-8656

[7] MLA Hamid, Ainul Faizin Abdul, Bambang Eka Purnama, dan Indah Uly Wardati. 2016. Sistem Informasi Penjualan Produk Unggulan Berbasis Website Pada Dinas Koperasi Perindustrian dan Perdagangan Kabupaten Pacitan. IJNS-Indonesian Journal on Networking and Security, Vol.4 No.3. 